\title{
Counselling in social work in Aotearoa New Zealand: Social workers' perspectives and practice
}

\author{
Barbara Staniforth
}

This article is the second of a two-part series which looks at the role of counselling in social work in Aotearoa New Zealand. This article examines a quantitative piece of research which asked approximately 1,000 members of the Aotearoa New Zealand Association of Social Workers for their beliefs around, and practice of, counselling in social work.

The first article reported on the historical and socio-cultural elements that have shaped the development of counselling in social work from information collected through in-depth interviews. Both pieces of research formed part of a PhD dissertation entitled Past, Present and Future Perspectives on the Role of Counselling in Social Work in Aotearoa New Zealand completed in 2010.

\section{Introduction}

As the first article in this series demonstrated, the role of counselling in social work varies considerably from place to place. As social work educators we are routinely asked by students about the differences between counselling and social work, and 'can social workers do counselling?'. The role of counselling in social work in Aotearoa New Zealand has been a contentious one, sometimes linked to health/mental health social work and the drive for social work professionalisation. Two previous studies in the 1980s (Rochford \& Robb, 1981; Sheafor, 1982) indicated that many social workers considered 'casework' and 'counselling' to fall within their roles, but there have been considerable cultural and socio-political and economic changes in the country since the time of those studies. This article looks at the responses of members of the Aotearoa New Zealand Association of Social Workers (ANZASW) to a questionnaire which examined beliefs and practice of social workers in relation to counselling within social work. The results show clearly that members of this sample group believed that counselling falls within the roles of social work and that the majority of social workers were doing some counselling within their practice.

\section{Literature}

Much has been written from a theoretical point about counselling in social work in terms of its legitimacy (Abramovitz, 1998; Asquith, 2005; Blewett, 2007; Dore, 1999), where it fits within social work (Beddoe \& Maidment, 2009; Connolly \& Harmes, 2009; Maidment \& Egan, 2009; Weld \& Appleton, 2008) and skills development (Brearley 1995; Harms, 2007; Seden 1999, 2005). Given the large and contentious role that counselling within social work has played over time, there have been relatively few studies which have been undertaken to explore the thoughts and practice of social work practitioners. 


\section{Perspectives}

An international study was conducted in 2000-2001, looking at the professional ideologies and preferences in social work of a number of graduating social workers around the world (Australia, Brazil, Canada, Germany, Hong Kong, Hungary, Israel, UK, USA and Zimbabwe). Results from each country were published within a volume edited by Weiss, Gal \& Dixon (2003).

Students were asked to indicate their preferred type of practice, indicating their choice of direct practice (micro) or policy practice (macro). The editors stated that the studies revealed 'an overwhelming preference for the former' (Dixon, Weiss \& Gal, 2003, p. 223). Only the students from Zimbabwe demonstrated a preference for macro practice. Students in the Israeli study demonstrated the greatest preference for micro practice, followed by the UK and Germany.

Following on from these results, students were asked about their preferences for adopting certain forms of practice, with choices being: forensic, psychotherapeutic, policy practice, and brokering and material assistance. 'Psychotherapeutic intervention strategies were preferred by students surveyed in most countries' (Dixon, Weiss \& Gal, 2003, p. 223). The exceptions were those students in Zimbabwe and Brazil, who rated their first preference as policy-practice.

In terms of New Zealand research on the views of counselling in social work, Graeme Munford, counsellor and social worker, conducted a research project in 2000 in partial fulfilment of the Master of Counselling degree entitled, 'Counselling and Social Work Perspectives'. Through a series of semi-structured interviews with five counsellors and five social workers he set out to answer two questions: ' 1 . What is the relationship between social work and counselling? and 2. How do counsellors and social workers perceive any differences and similarities between these two fields of practice?' (Munford, 2000, p. 2).

Munford found that several themes emerged in his study around the issues of: professional identity, practice approaches, roles and tasks, professional and personal qualities, skills, techniques, values and ethics. He concluded that:

The study found that differences and similarities did exist in the way that counsellors and social workers perceived their practice in relation to each of these themes. The most notable differences involved the way the counsellors and social workers identified the tasks they performed in their role and their level of interventions with clients. However, there were clear similarities in the values and ethics that counsellors and social workers identified and the personal and professional qualities to which they related (Munford, 2000, pp. 20-21).

The following quotations from participants in Munford's study demonstrated that social workers tended to see their role as more inclusive and that the counselling aspect of their practice was part of what they did on a continuum of tasks rather than being an exclusive role or task.

There isn't a rigid demarcation; it's a continuum. At times social workers get down towards the counselling end of that continuum...but we don't always have the luxury to do that...social work is more of a generic focus recognising that individuals exist within a system with other people... (Cited in Munford, 2000, p. 17). 
Another social worker saw '...counselling as a sub-set of social work...also as a sub-set of clinical psychology and psychiatry. The counselling role is where those three professions interface' (cited in Munford, 2000, p. 16).

\section{Practice}

In 2004, the National Association of Social Workers (NASW), in partnership with the Center for Health Workforce Studies - University of Albany, conducted a national survey of licensed social workers throughout most of the USA. A random sample of 10,000 social workers was drawn from licensure lists from nearly all states and the District of Columbia. A response rate of $49.4 \%(n=4,489)$ was obtained (Whitaker, Weismiller \& Clark, 2006).

This study was conducted 'To better predict the adequacy and sufficiency of the social work labor force to meet the changing needs of society' (Whitaker, Weismiller \& Clark, 2006, p. 5) and was focused on obtaining a detailed profile of the social work workforce in the USA. One of the areas studied looked at the roles performed by the respondents.

The report found that:

Licensed social workers are most likely to be involved with the tasks of screening/assessment $(93 \%)$, information / referral (91\%), crisis intervention (89\%), individual counseling $(86 \%)$, and client education (86\%) (Whitaker, Weismiller \& Clark, 2006, p. 19).

Percentages refer to numbers of social workers in the study indicating their involvement with those tasks. The report went on to state that:

There are only four tasks that significant numbers of social workers report spending more than half of their time on: individual counseling (29\%), psychotherapy (25\%), case management (12\%), and screening/assessment (10\%). Fewer than10 percent of social workers report spending more than half their time on any other task (Whitaker, Weismiller \& Clark, 2006, p. 191).

In terms of the practice of social work in Aotearoa there have been two pieces of research (Rochford \& Robb, 1981; Sheafor, 1982) which looked at the roles and tasks that a group of social workers performed within their practice. In 1979, the New Zealand Social Work Training Council commissioned a report on the social work workforce. The product, 'People in the Social Services. A New Zealand Survey', by Rochford \& Robb (1981) became the first major study to explore various dimensions of the social work workforce in Aotearoa. The focus of the project was to identify the social service populations, and then to examine the needs of that population in more depth. This study came out of a concern that 'the standards of training for social service workers were not adequate for the tasks social service workers were required to undertake' (Rochford \& Robb, 1981, p. 5).

Soon after the completion of the Rochford and Robb study, Massey University made application for an American scholar in social work education to receive a Fulbright Award to provide consultation to the social work programme in regards to developing curricula and in developing their MSW Programme. Dr Bradford Sheafor was given the award, for an appointment lasting for six months in 1982. As one of the tasks of Sheafor's appointment, he oversaw the completion of a major research project which looked at a job analysis of social workers in the lower half of the North Island. The overall objective of the study 
was to examine the fit between the content of social work jobs and the content of teaching provided through the Massey Social Work programme.

Both studies used questionnaires, and both studies demonstrated that social workers from both sample sets were extensively involved in the provision of counselling, problem solving or casework interventions.

ANZASW keeps statistics on numbers of social workers who identify with certain areas of practice. In October of 2009, 710, or 18\% of the ANZASW data base social workers indicated that they were involved in counselling within their jobs (ANZASW membership data base).

\section{Methodology}

The data for this article came out of the second part of the larger research project looking at past, present and future perspectives on the role of counselling in social work. The first part of the larger project involved a set of semi-structured in-depth interviews which occurred with social workers, counsellors, psychologists and educators. These interviews occurred between November of 2005 and Sept of 2006 and they are reported on in the previous article. The second part of the research was quantitative in nature and used structured questionnaires. There were also open-ended questions which allowed respondents to provide some qualitative feedback within the questionnaires. Development of this questionnaire was done in consultation with the Tangata Whenua Takawaenga o Aotearoa caucus, the Pacific Island and Chinese Social Worker interest groups of the ANZASW. The questionnaire was also piloted with social workers representing various parts of the social service sector.

The final version of the questionnaire comprised 28 questions which looked at four main areas: 1) beliefs about the appropriateness of counselling within social work; 2) Participants' understanding of the use of the terms social work and counselling and their use of counselling or counselling skills within their practice; 3) Their need or want for training in the area of counselling in social work; and finally 4) Demographic information.

Ethics approval was given for the quantitative aspect of the project through the Massey University Human Ethics Committee in December of 2005. ANZASW provided a randomly computer-generated list of 1,000 of its members (approximately one third of the membership at that time) from an Excel database. Questionnaires were mailed out in January 2007 with a follow-up reminder sent in March of 2007.

Of the original 1,000 names provided, 44 responses were invalid due to incorrect addresses being provided or to questionnaires being returned unopened. A total of 404 completed and valid questionnaires were returned for a total response rate of 404/956 (42.3\%, margin of error $=+/-5 \%)$.

Demographic variables within the project sample had good consistency with the ANZASW membership in the areas of gender, age, educational qualifications and fields of practice. Māori were underrepresented in the project sample but there were difficulties in being able to compare ethnicity as there were about $28 \%$ of the ANZASW membership who had not stated their ethnicity. There was also a difficulty in that the demographic data obtained for 
the sample pool was for the year 2009 while the study sample was obtained in 2007. These factors influence the ability to state that the results are generaliseable across all ANZASW members. The questionnaires also did not go out to social workers who were not members of ANZASW so results cannot be generalised across the sector.

Respondents were invited to participate through an introductory information sheet. This information sheet provided the following definition of counselling for them to consider while answering the questions:

A therapeutic process involving interaction between a counsellor and a client aimed at enhancing the quality of the client's life by assisting them to overcome relationship difficulties, to deal with the consequences of trauma, to cope better with difficulties encountered in relationships in the workplace, or to change patterns of behaviour that are actually or potentially harmful to the client or others (Ludbrook, 2003, p. 4).

Respondents were asked to indicate their degree of belief in various statements, and then to later indicate the degree of counselling done in their roles. Qualitative data was also provided through an open-ended question which allowed for any further comments. Some of these comments are used in this article to support the quantitative results. Data from fixedformat questions reported on in this article was analysed using The Statistical Package for the Social Sciences (SPSS-Version 14).

The SPSS data file was checked for inconsistencies and any apparent errors. From the cleaned file, univariate statistics (frequencies) were run. When multiple responses were provided within one question, the percentage of cases was reported as well as the number of responses.

Bivariate analysis or cross tabulations of questions were done in relation to the following variables:

- Age of respondents

- Gender of respondents

- Years of practice in social work

- Ethnicity

- Educational qualifications

- Spiritual affiliation

- Born in NZ or overseas

- Sector of practice

- New Zealand or overseas qualified

In terms of descriptive statistics, phi has been reported and used for nominal variables and Gamma coefficient has been reported and used for ordinal variables (Sarantakos, 2005). Differences have been reported as statistically significant when the $\mathrm{p}$ value is less than .05 .

\section{Results}

The research reported on in this article considers those parts of the questionnaire that specifically dealt with social workers' perspectives on, and practice of, counselling in social work. 
For further and more complete information about the study please refer to Staniforth (2010) or Staniforth, Fouché and O'Brien (2011, in press).

\section{Perspectives}

Table 1 summarises the results of the questions which asked for social workers' perspectives of the role of counselling in social work.

Table one. Perspectives on counselling in social work.

Statement

\begin{tabular}{|c|c|c|c|c|c|c|}
\hline 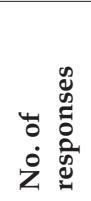 & 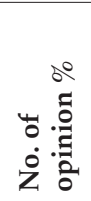 & 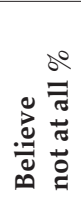 & 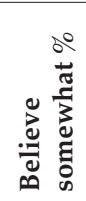 & 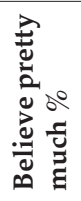 & 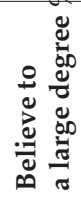 & 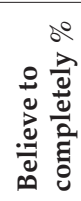 \\
\hline
\end{tabular}

Social workers who are only doing counselling are still doing social work

401

1

19

26

13

23

18

Counselling falls within the role of social work within many fields of practice

401

Social workers should be able to use counselling skills in their work, but not do counselling

Social workers should not be engaged in counselling

Social workers should not be encouraging change in individuals. They should be engaged in making change at more systemic levels

Social workers are not properly trained to perform these tasks

Results from the table columns are discussed below. Data from the open-ended final question is also presented to support the quantitative information.

\section{Social workers who are only doing counselling are still doing social work}

This result shows that only $19 \%$ of respondents believed that social workers who only did counselling were not really doing social work, with $80 \%$ of respondents believing that it was possible to engage in counselling only and still call oneself a social worker. This is a very important point as it demonstrates that a clear majority of respondents believed that if one only did counselling within one's practice one was still doing social work. Cross tabulations revealed no statistically significant differences between groups within this statement.

In terms of the responses to the open-ended question provided by the respondents, those who had trained overseas made comments in regards to the different perception here regarding whether social workers should be doing, or did do, therapy or counselling: 
I believe in New Zealand practitioners draw a distinct line between counselling and psychotherapeutic skills. This is not the case in many European countries. In my answers I have tried to not discriminate between counselling and psychotherapy as I believe they are on a continuum. I believe that social work and counselling in its broadest sense should be seen as different aspects of the same profession - as they are seen in some others countries.

Social work is a core mental health profession where I am from ( $3 / 4$ of mental health workers are social workers). I was surprised that this is very different in NZ. It seems to be more linked with the benefit and CYF.

Some respondents also indicated that counselling could be the main role of the social worker, but that this would usually sit within the brief of being a 'specialty' within social work, or would fall under the brief of 'clinical' social work.

I believe SWs can do counselling and that those who do only counselling are not general SWs but specialists.

From my viewpoint - counselling is an integral practice component of SW practice and can specifically form the basis of what can be described as 'clinical social work'.

Some respondents identified as practitioners in private practice.

As a social worker of 30 years I am now offering a private s/ work service. This involves a lot of counselling but as your research has shown, $\mathrm{s} /$ work is seen as the 'poor relation' to counsellors. I do not hold with this view personally, and have a very successful outcomes private practice.

\section{Counselling falls within the role of social work in many fields of practice}

Results here were fairly unequivocal with only $4 \%$ of respondents not believing this statement and the largest percentage of respondents (31\%) believing this completely.

Cross tabulation revealed that there were two areas which demonstrated some statistically significant differences in terms of belief on this statement, namely education level and being trained in New Zealand versus overseas. The cross tabulations reveal a weak positive relationship between education level and belief in the statement (gam$\mathrm{ma}=0.175, \mathrm{p}<.05$ ) with good generalisability (significance 0.15 ). Social workers with a graduate degree (48\%) were more likely to believe the statement completely than those at diploma level (29\%) and BSW graduates (30\%). As only 32 of 337 respondents were trained overseas, results for the cross tabulation of 'where trained' are indicative only. There is a weak relationship ( $\mathrm{Phi}=0.184, \mathrm{p}<.05$ ) with overseas trained social workers believing this statement more completely; nearly half $(47 \%)$ of overseas trained respondents believed this while just over a quarter (29\%) of New Zealand trained respondents believed it.

Social workers should be able to use counselling skills in their work, but not do counselling Thirty-six percent of respondents did not believe this statement at all, while the majority $(61 \%)$ of respondents believed this to some degree. There was a fairly equal distribution across the other levels of agreement. None of the cross-tabulated results demonstrated any statistically significant differences between groups in this area and distribution across sectors also appears to be fairly consistent as well. 


\section{Social workers should not be engaged in counselling}

Only $15 \%$ of respondents believed this somewhat, with diminishing percentages believing this to any greater degree. There were several cross tabulations which revealed statistically significant differences between groups.

Disbelief increased with higher levels of education achieved, as reflected in a weak negative gamma relationship of $-0.194(\mathrm{p}<.05)$. Social workers with postgraduate-level training were most likely to not believe the statement at all (80\%) while $72 \%$ of BSW graduates did not believe the statement at all and $64 \%$ of diploma-level graduates did not either.

There is a weak to moderate association between ethnicity and belief in this statement (Phi $=0.272, \mathrm{p}<.001)$. Māori are more likely to believe this statement than European or other ethnic groups. Nearly $10 \%$ of Māori believed this statement completely compared to $0 \%$ 'Other' ethnicity and $0.7 \%$ of Pakeha respondents. Conversely, only $57 \%$ of Māori did not believe at all compared with $69 \%$ of Pakeha and $83 \%$ of 'Other' ethnic groups.

Statistically significant differences were noted when this statement was cross tabulated with gender. There is a weak relationship with gender (Phi $=0.175, \mathrm{p}<.05)$. Males tend to not believe this statement to a greater degree than females ( $80 \%$ compared to $68 \%$ respectively).

As only 31 of the respondents were trained overseas, results for this cross tabulation are indicative only. There appears to be a weak relationship with place of training (Phi $=0.185$, $\mathrm{p}<.05)$. These results tend to indicate that overseas-trained social workers 'do not believe this statement at all', to a greater degree $(94 \%)$ than NZ-trained social workers $(66 \%)$.

Social workers should not be encouraging change in individuals. They should be engaged in making change at more systemic levels

The clear majority of respondents $(84 \%)$ did not believe this statement at all.

There is a weak relationship revealed with the cross tabulation with gender $(\mathrm{Phi}=0.167$, $\mathrm{p}=.05$ ). While males and females appeared to disbelieve the statement at a similar rate (females $84 \%$, males $86 \%$ ), these results show that females were more likely to believe the statement at the 'believe somewhat' level $(12 \%)$ compared with males who believed it in $6 \%$ of cases at this level.

\section{Social workers are not properly trained to perform these tasks}

Sixty-seven percent of respondents indicated that they had some degree in the belief that social workers were not properly trained to perform counselling tasks. However, belief was not strong, as the greatest response was found in the 'believe this somewhat' category with $45 \%$ of respondents indicating this belief, and only $22 \%$ believing more strongly.

There were no results with statistical significance yielded through the cross tabulation for this statement.

\section{Counselling in practice}

As part of determining if agencies subscribed to social workers doing counselling, or saw this as a valid social work role, respondents were asked if counselling was included in their job 
description. The majority of respondents (60\%) indicated that counselling was not included in their job descriptions, $31 \%$ said that it was within their job description, and $9 \%$ did not know $(n=357)$. Still there is a large proportion of social workers with counselling in their job descriptions which indicates some degree of sanctioning from respondents' employers about the use of counselling within their jobs.

Cross tabulation with number of years in practice yielded some statistically significant differences. There is a weak association $(\mathrm{Phi}=0.270, \mathrm{p}<.001)$ with social workers having been in the field for more than 21 years being most likely to have counselling in their job description $(51 \%)$. Similarly, cross tabulation with age of respondent showed a weak relationship $(\mathrm{Phi}=0.170, \mathrm{p}<.03)$ with older social workers being more likely to have counselling within their job description. Thirty-nine percent of those over the age of fifty-one indicated that they had counselling within their job description as opposed to $32 \%$ of those in the 41-50 year-old group and $25 \%$ of those in the 20-40 year-old group. There is likely to be a strong relationship between respondent age and length of time in practice in many cases.

There was a relationship between gender and having counselling within one's job description with men being more likely to indicate that they had counselling within their job description $(44 \%)$ compared with only $30 \%$ of women (Phi $=0.124, \mathrm{p}=.05)$.

Figure 1 reveals results to the question that asked respondents about the amount of counselling done within their jobs.

Figure one. What social workers do.

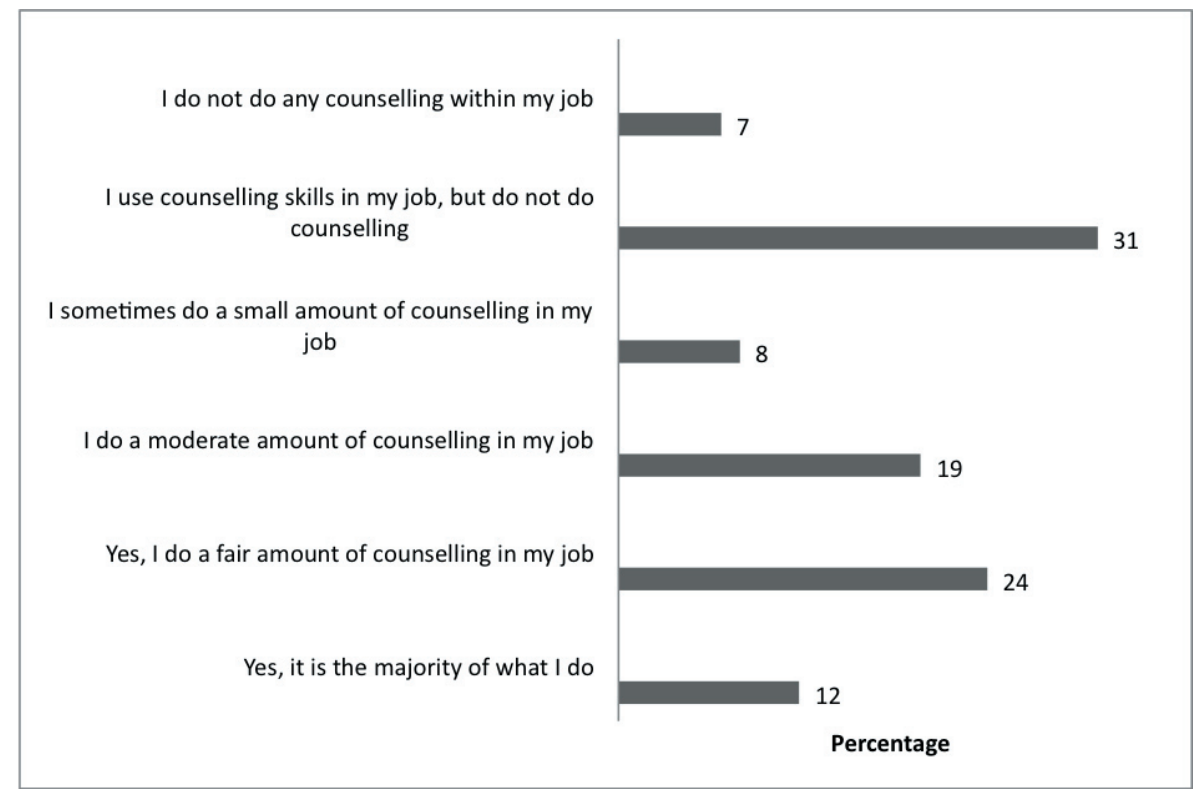

$\mathrm{N}=396$. $\mathrm{Nb}$ Percentages are rounded so do not add up to $100 \%$. 
Cross tabulations did not reveal any statistically significant differences between the various groups.

Several of the questionnaire respondents further discussed their practice within the openended questions of the questionnaires. Some of the respondents emphasised the difference they felt existed between using counselling skills and doing counselling:

While counselling skills are utilised on a daily basis, I find at times a therapeutic component is often present but I am always vigilant to not be placed in a situation as a counsellor.

I am a social worker who has counselling skills. As I have no counselling qualifications I would not identify myself as a counsellor. Certainly within the role of a social worker you use counselling/therapeutic skills.

One respondent commented upon the need for clients to have a baseline level of need met in order to partake of the counselling experience. Maslow's hierarchy of needs (Maslow, 1943) is used at times to demonstrate the need for good social work intervention prior to any counselling-type activity being of use.

I work from a strength based approach-counselling the client to find their own strength while supporting them to make changes to their situation. My clients are long term, therefore to build a good working relationship some counselling is needed to gain an understanding of the client. I see with my clients that counselling does not occur until basic need and safety are met e.g. housing, money, safety. I believe that for a client to be able to fully participate in counselling they need to have built trust, faith that change can happen, safety of themselves and loved ones, and have enough money to live.

One respondent indicated that the role of social work within her statutory organisation had shifted significantly over time, and that the work of counselling was now often contracted out:

Working at CY\&F has changed dramatically over the last 20yrs and where we were encouraged to engage with families and provide counselling, due to the intense case-load, directive work and increased negative attitude towards staff from our clients and public, it is more difficult to engage with families / clients and individuals. This type of work is most often contracted to therapists or other agencies.

One respondent discussed the importance of workers knowing their limitations in regards to their skills:

My work is in counselling. However there is a component of my work that is social work. I have worked in multi-disciplined teams. I don't believe you can practise social work without incorporating counselling and vice versa. I believe whether we practise as counsellors or social workers, we must know when to refer on to enable maximum benefit for clients.

Finally, one respondent, working on a multidisciplinary team in mental health discussed how her skills in counselling likely helped her provide excellent service to her clients, by virtue of the mix with her social work background:

I work as a care manager in a CMHT (community mental health team sic) and also provide counselling for depression and anxiety. I find that I struggle to explain my role as social 
worker and often members of my team (MDT) are also unclear about what I do. I think this is because of the counselling/social work mix. I would have felt more confident if there was a stronger counselling component in my training (instead I have up skilled myself). I think I am a better social worker and give added value to my clients because I am able to provide the extra counselling. Furthermore, because I come from a social work background, that means I support clients to access community resources - that I know about - which pure counsellors or psychologists do not.

\section{Discussion}

While confusion still reigns as to the role of counselling in social work in terms of where it sits or should sit in Aotearoa New Zealand, the respondents to the research reported on in this article seem for the most part clear. Most respondents indicated that they believed that social workers who only did counselling were still doing social work, that counselling fell within the brief of social work in many fields of practice, and they did not believe that social workers should not be engaged in counselling. There was some discrepancy evident between the idea of 'doing counselling' and 'using counselling skills'. This would be a useful concept to explore further in a more in-depth way. Preliminary data here seems to suggest that there is a trend towards those with higher education, those coming from or trained overseas, tauiwi and men having stronger beliefs in the appropriateness of the role of counselling in social work. These findings should also be examined further, but they tend to support the view of counselling sitting within more 'professionally' oriented Western frameworks as discussed in part 1 of this series (Staniforth, Fouché \& O’Brien, in press).

In terms of what social workers are doing in their practice, approximately one third of respondents indicated that the role of counselling was contained within their job descriptions. Only 7\% of respondents indicated that they did no counselling in their jobs. Again there is some difference between those $(31 \%)$ who indicated that they 'used counselling skills in their jobs, but did not do counselling' and those $(63 \%)$ who indicated doing from 'small amount' of counselling to it being the 'majority of what they did'. Given that $67 \%$ of respondents indicated that they didn't believe that social workers were adequately trained to perform these tasks, this is of some concern.

\section{Conclusion}

Aotearoa New Zealand has gone through several social, cultural and economic changes since the beginning of the establishment of the social work association in 1964. The role of counselling within social work has flowed and evolved along with these changes. The two previous studies in the 1980s (Rochford \& Robb 1981; Sheafor 1982) demonstrated that at that time counselling and social casework formed a large and legitimate part of the social work brief within their samples. The results from this study demonstrate that for at least the 401 respondents of the research discussed in this article, counselling remains a legitimate form of social work practice both in terms of their perspectives and their practice.

It is hoped that these results will help ignite a broader debate about where counselling should sit within the profession of social work and support the development of scopes of practice which identify the parameters of counselling in social work and within various fields of practice. It is also hoped that these debates may yield clearer guidelines for social work educators, social workers, their employers and service users in terms of what levels 
of counselling skills competency can be expected. The call goes out to ANZASW, The Social Workers Registration Board and schools of social work in Aotearoa New Zealand to work together to help bring about this clarity.

The authors wish to acknowledge the ANZASW and all the members who took part in the research described in this article.

\section{References}

Abramovitz, M. (1998). Social work and social reform: An arena of struggle. Social Work, 43(6): 512-526.

Asquith, J., Clark, C., \& Waterhouse, L. (2005). The role of the social worker in the 21st century. Retrieved 13/09/08, from http:/ / www.scotland.govt.uk/Resource/Doc/47121/0020658.pdf.

Beddoe, L., \& Maidment, J. (2009). Mapping knowledge for social work practice. Critical intersections. South Melbourne: Cengage Learning.

Blewett, J. Lewis, J., \&Tunsill, J. (2007). The changing roles and tasks of social work. Retrieved 16/09/08, from http:/ / www.gscc.org.uk/ NR/ rdonlyres / 8BE06845-9895-465B-98C2-31CF227D7422/0/SWrolestasks.pdf.

Brearley, J. (1995). Counselling and social work. Bristol: Open University Press.

Connolly, M., \& Harms, L. (Eds.). (2009). Social work. Contexts and practice (2nd ed.). South Melbourne: Oxford University Press.

Dixon, J., Weiss, I. \& Gal, J. (2003). Professional ideologies and preferences: A global and comparative perspective. In I. Weiss, J. Gal \& J. Dixon (Eds.) Professional ideologies and preferences in social work: A global study (pp. 215-226). Westport: Praegar.

Dore, M. (1999). The retail method of scoail work: The role of the New York School in the development of clinical practice. Social Service Review, 73(2): 169-190.

Harms, L. (2007). Working with people. Communication skills for reflective practice. South Melbourne: Oxford University Press.

Lang, S. (2005). 'Decolonialism' and the counselling profesion: The Aotearoa/New Zealand experience. International Journal for the Advancement of Counselling, 4: 557-572.

Ludbrook, R. (2003). Counselling and the law. Hamilton: New Zealand Association of Counsellors. Te Ropu Kaiwhiriwhiri o Aotearoa.

Maidment, J., \& Egan, R. (Eds.). (2009). Practice skills in social work \& welfare. More than just common sense (2nd ed.). Crows Nest: Allen \& Unwin.

Maslow, A. H. (1943). A theory of human motivation. Psychological Review, 50: 370-396.

Munford, G. (2000). Counselling and social work perspectives. Unpublished research project, Massey University, Palmerston North, New Zealand.

Rochford, M., \& Robb, M. (1981). People in the social services. A New Zealand survey. Wellington: Social Work Training Council.

Sarantakos, S. (2005). Social research (3rd. ed.). Basingstoke: Palgrave Macmillan.

Seden, J. (1999). Counselling skills in social work practice. Buckingham: Open University Press.

Seden, J. (2005). Counselling skills in social work practice (2nd ed.). Maidenhead: Open University Press.

Sheafor, B. (1982). Social work practice in New Zealand. An analysis for education and training curriculum development. Palmerston North: Massey University.

Staniforth, B. (2010). Past, present and future perspectives on the role of counselling in social work in Aotearoa New Zealand. Unpublished doctoral dissertation. Massey University, Auckland, New Zealand.

Staniforth B., Fouché, C. \& O'Brien, M. (In press). Counselling in social work in Aotearoa New Zealand: The historical, political and socio-cultural evolution. Aotearoa New Zealand Social Work Review.

Staniforth, B., Fouché, C. \& O’Brien, M. (In press). Still doing what we do: Defining social work in Aotearoa New Zealand. Journal of Social Work.

Weiss, I., Gal, J. \& Dixon, J. (Eds.) (2003). Professional ideologies and preferences in social work: A global study. Westport: Praegar.

Weld, N., \& Appleton, C. (2008). Walking in people's worlds. Auckland: Pearson Education New Zealand.

Whitaker, T., Weismiller, T., \& Clark, E. (2006). Assuring the sufficiency of a frontline workforce: A national study of licensed social workers. Executive summary. Washington D.C.: National Association of Social Workers: Center for Workforce Studies. 